\title{
Article
}

\section{Starch Formates: Synthesis and Modification}

\author{
Sascha Blohm ${ }^{1}$, Thomas Heinze ${ }^{1, *(1)}$ and Haisong Qi $^{2}$ (I) \\ 1 Centre of Excellence for Polysaccharide Research, Institute for Organic Chemistry and Macromolecular \\ Chemistry, Friedrich Schiller University Jena, Humboldtstraße 10, D-07743 Jena, Germany; \\ sascha.blohm@uni-jena.de \\ 2 State Key Laboratory of Pulp and Paper Engineering, South China University of Technology, \\ Guangzhou 510640, China; qihs@scut.edu.cn \\ * Correspondence: thomas.heinze@uni-jena.de; Tel.: +49-3641-948270
}

Citation: Blohm, S.; Heinze, T.; Qi, H. Starch Formates: Synthesis and Modification. Molecules 2021, 26, 4882. https://doi.org/10.3390/molecules 26164882

Academic Editors: Janusz Kapusniak and Idalina Gonçalves

Received: 21 July 2021

Accepted: 11 August 2021

Published: 12 August 2021

Publisher's Note: MDPI stays neutral with regard to jurisdictional claims in published maps and institutional affiliations.

Copyright: (c) 2021 by the authors. Licensee MDPI, Basel, Switzerland. This article is an open access article distributed under the terms and conditions of the Creative Commons Attribution (CC BY) license (https:// creativecommons.org/licenses/by/ $4.0 /)$.

\begin{abstract}
Starch can be efficiently converted into the corresponding formates homogeneously using $N$-formyl imidazole obtained by the reaction of $1,1^{\prime}$-carbonyldiimidazole and formic acid in dimethyl sulfoxide as a solvent. Starch formates are soluble in polar aprotic solvents, not susceptible against hydrolysis, and not meltable. Thermoplastics could be generated by conversion of starch formates with long-chain fatty acids exemplified by the conversion with lauroyl chloride in $N, N$-dimethylacetamide, leading to mixed starch laurate formates. The mixed esters show melting temperatures mainly dependent on the amount of laurate ester moieties.
\end{abstract}

Keywords: starch; esterification; starch formate; mixed starch ester; thermoplastic

\section{Introduction}

Polysaccharide esters play an important role in various fields of application, e.g., as foils, films, filters, and thermoplastic to replace plastics based on fossil resources. Thermoplastic starch may be obtained by derivatisation with long-chain fatty acids that yields a disturbance of the intra- and intermolecular hydrogen bonds of the polysaccharide [1-3]. While polysaccharide esters of a broad variety of carboxylic acids are known and even commercially produced, the formic acid ester is scarcely investigated up until now. It was shown that organo-soluble formates of cellulose could be easily synthesised and used for esterification with other carboxylic acids [4]. Moreover, formic acid is able to dissolve carboxymethyl cellulose by acylation of the remaining hydroxyl groups [5].

Starch formate was obtained by the reaction of starch with formic acid [6-15]. However, the reaction is highly sensitive even to traces of water [8] and leads to starch formate with low average degrees of substitution (DS) only $[6,7,10]$. Up to now, the highest DS value of starch formate known was 2.14 and was reached at extended reaction time, high temperature, with extensively dried starch, and the use of a high excess of concentrated formic acid [8]. Unfortunately, on one hand, both formic acid chloride and -anhydride are difficult to handle under usual conditions. On the other hand, the reaction of formic acid with $1,1^{\prime}$-carbonyldiimidazole (CDI) has been described, resulting in $N$-formyl imidazole [16]. $\mathrm{N}$-formyl imidazole is stable up to about $60^{\circ} \mathrm{C}$ and rather sensitive to hydrolysis. Nevertheless, it is highly reactive concerning alcohols. Thus, in the present study, it was investigated to prepare a formic acid ester of starch with a high degree of substitution (DS), applying $\mathrm{N}$-formyl imidazole. Moreover, the properties of the starch formates, including subsequent esterification, were studied.

\section{Results}

A mixture of formic acid and 1,1'-carbonyldiimidazole (CDI) was allowed to react in dimethyl sulfoxide (DMSO) to form the $\mathrm{N}$-formyl imidazole. Subsequently, the $\mathrm{N}$-formyl imidazole was added to a solution of starch (1) in DMSO at an elevated temperature (Figure 1). 


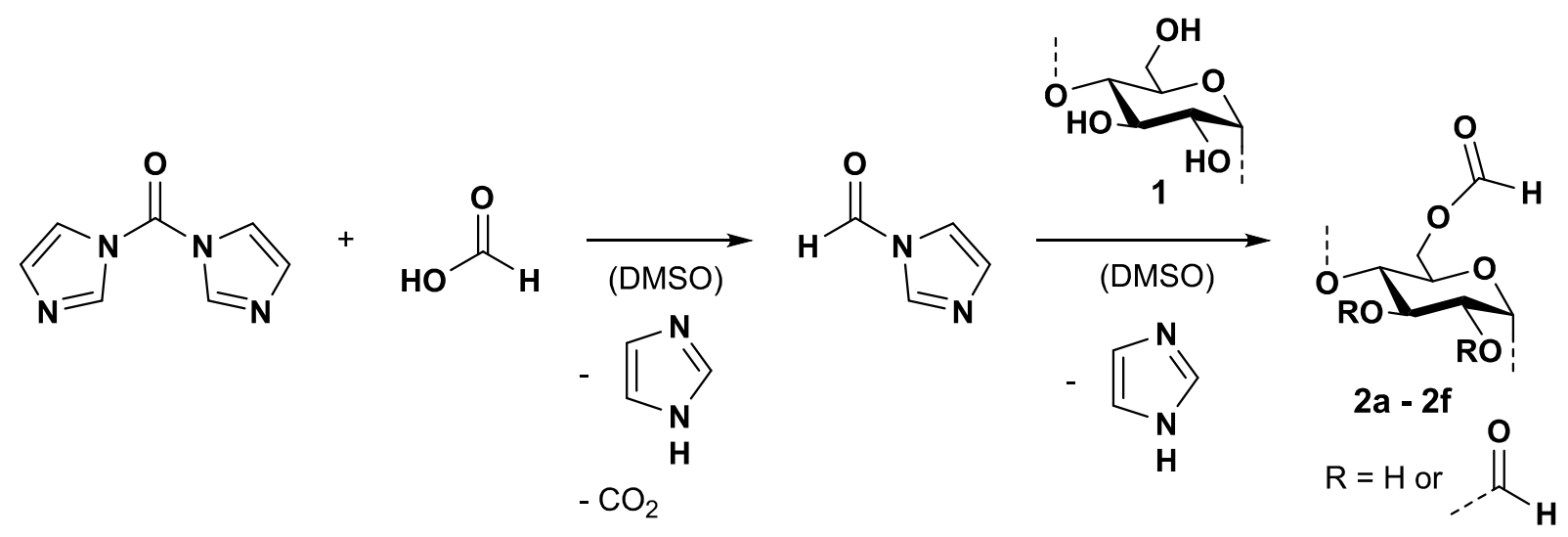

Figure 1. Scheme for the reaction of starch (1) with formic acid and 1,1'-carbonyldiimidazole yielding $N$-formyl imidazole in dimethyl sulfoxide.

\subsection{Synthesis and Characterisation of Starch Formates}

Starch formate samples with degrees of substitution (DS) in the range from 0.97 to 2.55 (16 h reaction time) could be obtained by the reaction shown in Figure 1. A high DS could be realised by applying a fivefold excess of formic acid and CDI related to the anhydroglucose unit (AGU), even within a 3-h reaction time at $60^{\circ} \mathrm{C}$ (Table 1). Up to now, the highest DS value of starch formate known was 2.14 and was reached at an extended reaction time, high temperature, with extensively dried starch, and the use of a high excess of concentrated formic acid [8]. Other attempts published in the literature with less concentrated formic acid or less dried starch led to a limitation of the DS of about 1.

Table 1. Conditions for and results of the reactions of starch (1) with $N$-formyl imidazole obtained by the conversion of formic acid and 1,1'-carbonyldiimidazole in dimethyl sulfoxide.

\begin{tabular}{cccccc}
\hline \multirow{2}{*}{$\begin{array}{c}\text { Sample } \\
\text { No. }\end{array}$} & $\begin{array}{c}\text { Temp. } \\
{\left[{ }^{\circ} \mathbf{C}\right]}\end{array}$ & $\begin{array}{c}\text { Meaction Conditions } \\
\text { AGU:Formic Acid:CDI }\end{array}$ & $\begin{array}{c}\text { Time } \\
{[\mathbf{h}]}\end{array}$ & DS & $\begin{array}{c}\text { Starch Formate } \\
{[\%]}\end{array}$ \\
\hline $\mathbf{2 a}$ & 60 & $1: 1: 1$ & 3 & 0.97 & 97 \\
$\mathbf{2 b}$ & 60 & $1: 2: 2$ & 3 & 1.86 & 93 \\
$\mathbf{2} \mathbf{c}$ & 60 & $1: 3: 3$ & 3 & 2.15 & 72 \\
$\mathbf{2 d}$ & 60 & $1: 5: 5$ & 3 & 2.44 & 49 \\
$\mathbf{2 e}$ & 50 & $1: 3: 3$ & 3 & 1.99 & 66 \\
$\mathbf{2 f}$ & 50 & $1: 5: 5$ & 16 & 2.55 & 51 \\
\hline
\end{tabular}

The starch formates obtained in the present studies were characterised by means of FTIR- and NMR spectroscopic measurements. A typical FTIR spectrum of sample 2d, including the signal assignments, is shown in Figure 2. The vibrational bands of the intraand intermolecular $\mathrm{O}-\mathrm{H}$ bonds are not particularly intense, which fits the high DS of the sample. On the contrary, the dominant band of the carbonyl vibration is clearly visible at $1727 \mathrm{~cm}^{-1}$, which is a typical value for formic acid esters [17].

The ${ }^{13} \mathrm{C}$ NMR spectra of starch formate samples of different DS values are displayed in Figure 3. The signals of the AGU are found in the range of 60-100 ppm. For sample 2a of the lowest DS value, there is only one signal visible at $99.95 \mathrm{ppm}$ for position 1 of the AGU without an esterified neighboring position 2 . The signal at $79.00 \mathrm{ppm}$ can be assigned to position 4 . The signals for carbon atoms 2 and 3 without substituents and those of carbon atom 5 can be observed at 73.11 ppm, 71.56 ppm, and 69.94 ppm, respectively. 


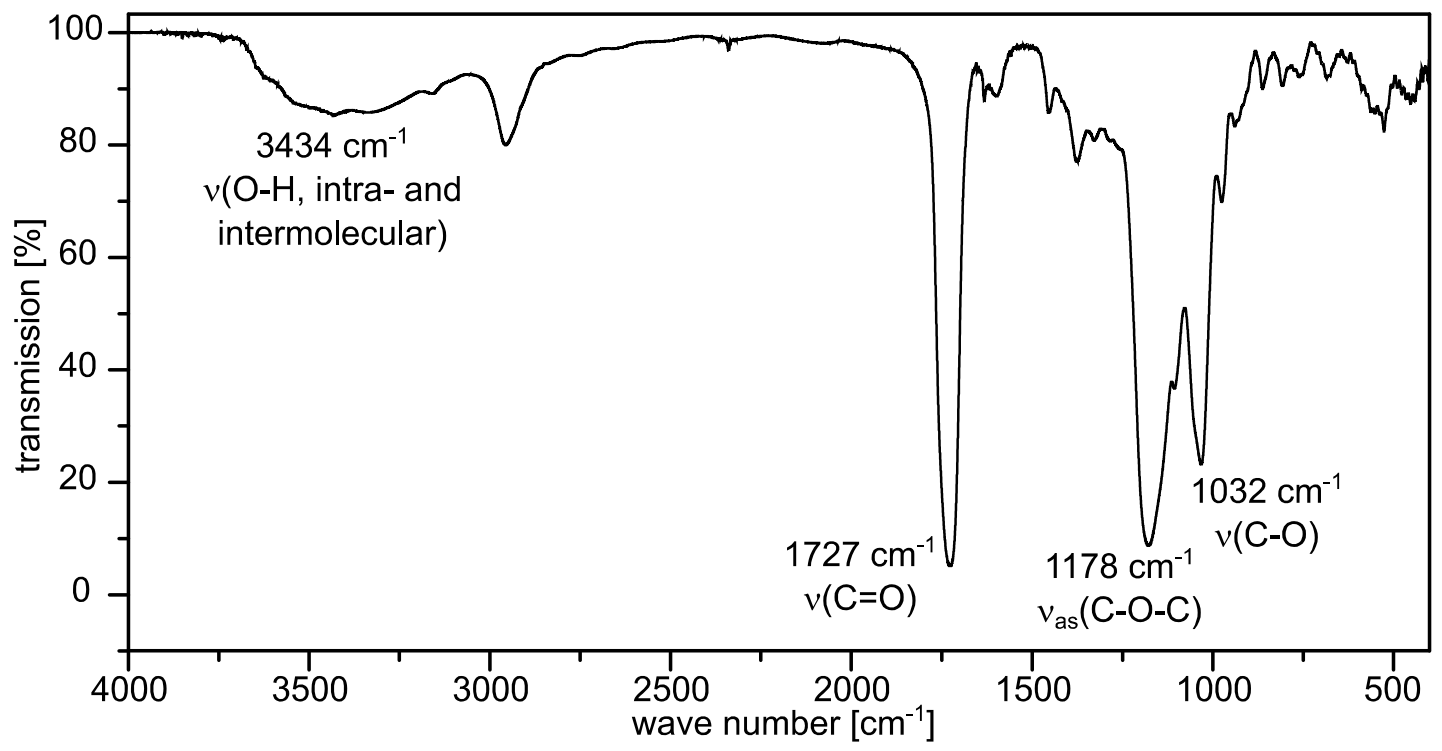

Figure 2. FTIR spectrum $\left(\mathrm{KBr}\right.$, resolution $1 \mathrm{~cm}^{-1}, 64$ scans) of starch formate $2 \mathbf{d}$ (degree of substitution $\left.=2.44\right)$.

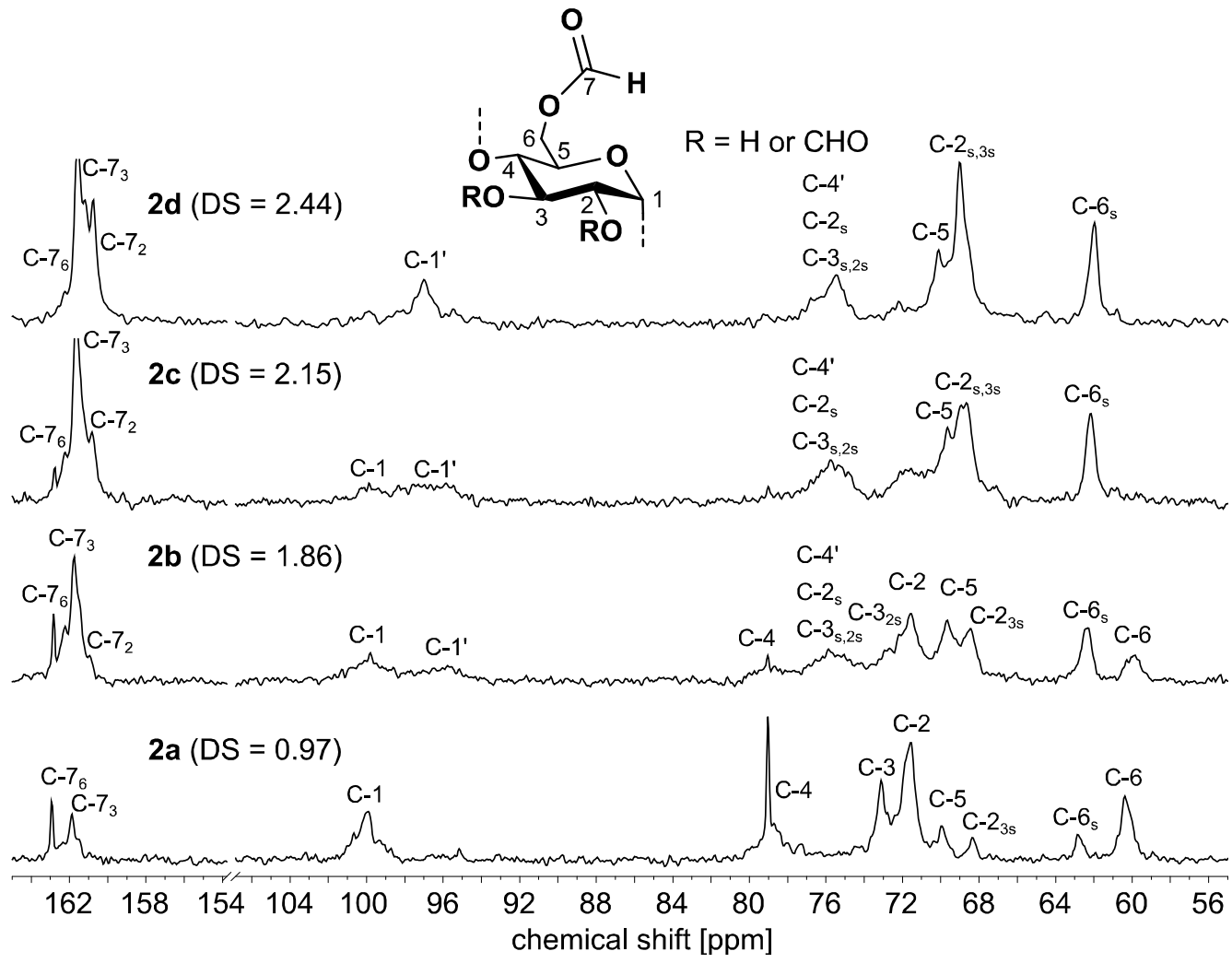

Figure $3 .{ }^{13} \mathrm{C}$ NMR spectra $\left(62.90 \mathrm{MHz}, 323 \mathrm{~K}\right.$, DMSO- $\left.d_{6}\right)$ of starch formates of different degrees of substitution (DS).

Position 3 with esterified position 2 adjacent is represented by the signal at $68.35 \mathrm{ppm}$. The signals at $62.85 \mathrm{ppm}$ and $60.38 \mathrm{ppm}$ can be assigned to position 6 , which is esterified and unchanged. From these signals, it can be concluded that positions 3 and 6 of the AGU preferentially participate in the reaction with $N$-formyl imidazole. The sample 2b with a DS of 1.86 possesses an unambiguous signal at $95.70 \mathrm{ppm}$ for a carbon atom in position 1 with the neighboring esterified position 2. With increasing DS, position 6 becomes completely esterified (sample 2c), and at a high DS of 2.44, position 2 is also almost completely esterified. 


\subsection{Properties of Starch Formates}

To investigate the hydrolytic stability of the starch formates, sample $\mathbf{2} \mathbf{d}$ was treated in a mixture of $\mathrm{N}, \mathrm{N}$-dimethylformamide (DMF) and water under stirring and the $\mathrm{pH}$ value was controlled continuously. The concentration was chosen to reach a $\mathrm{pH}$ value of 1 in the case of complete hydrolysis. Even after three hours, however, no deviation from the $\mathrm{pH}$ value of 7 was observed.

Independent of the DS, the starch formate samples obtained were soluble in polar aprotic solvents such as $\mathrm{N}, \mathrm{N}$-dimethylacetamide (DMAc), DMF, and DMSO. No melting could be detected for any of the starch formates at a temperature of up to $230{ }^{\circ} \mathrm{C}$, as evaluated by a hot stage microscope. It was of interest to study the pure starch formates. It might be possible to receive a thermoplastic product if a high amount of softener is added, which would lead to a complex, as well as economical and ecological, undesired system.

\subsection{Conversion of Starch Formate with Long-Chain Fatty Acid}

Starch formates were allowed to react with lauric acid chloride (Figure 4). In the course of the reaction, a partial split off of formate groups occurred, which presumably could happen due to transesterification or by the chloride ions contained in the reaction medium. The nucleophilic chloride ions may attack the carbonyl group of the formic acid ester, resulting in the formation of formic acid chloride, which is not stable and readily decomposes into hydrogen chloride and carbon monoxide.

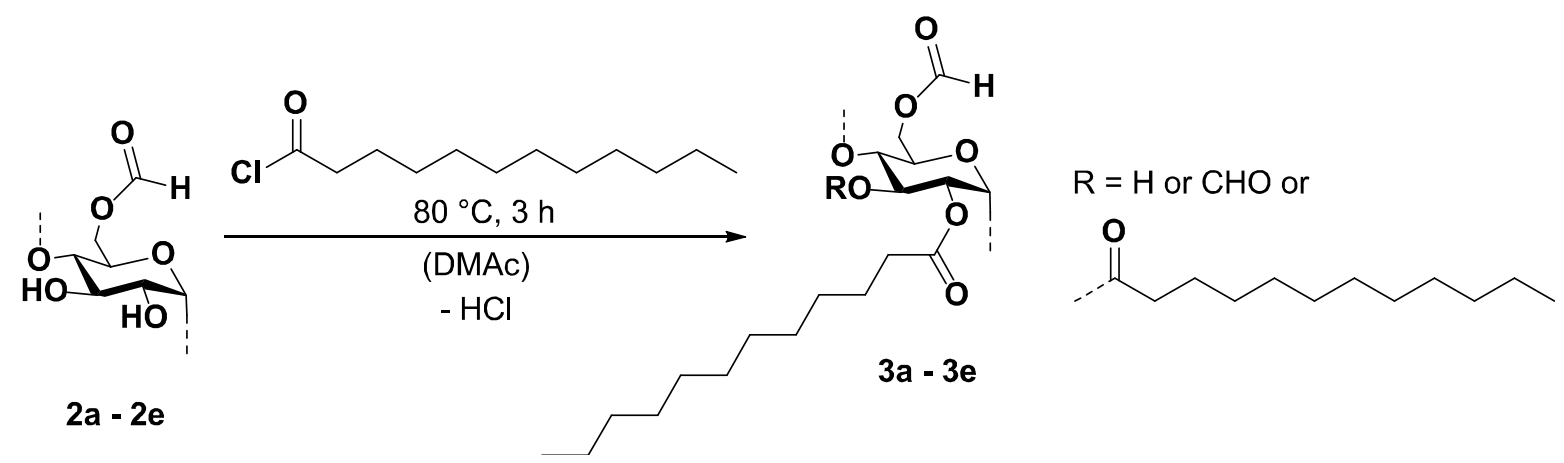

Figure 4. Scheme for the reaction of starch formates (2a-2e) with lauric acid chloride in $N, N$-dimethylacetamide.

Samples with total DS values (DS tot ) in the range from 1.47 to 3.00 (samples 3a-3d) were accessible (Table 2). A typical ${ }^{13} \mathrm{C}$ NMR spectrum of sample $3 \mathbf{a}$ is shown in Figure 5. The spectrum contains the typical signals for highly substituted starch fatty acid esters. The carbon atom of the fatty acid ester causes the signal at $173.35 \mathrm{ppm}$. Furthermore, the signals of the AGU can be detected at $95.93 \mathrm{ppm}$ as well as in the range from $72 \mathrm{ppm}$ to $69 \mathrm{ppm}$ and at $62.23 \mathrm{ppm}$. The methylene and methyl groups of the fatty acid moiety are represented by the signals at $34.06 \mathrm{ppm}, 32.07 \mathrm{ppm}, 29.70 \mathrm{ppm}, 24.96 \mathrm{ppm}, 22.81 \mathrm{ppm}$, and $14.23 \mathrm{ppm}$. Moreover, there is a signal at $160.65 \mathrm{ppm}$ that can be assigned to the carbon atom of the formic acid ester.

The solubility of starch formate laurates depends on the partial DS values. A high $\mathrm{DS}_{\text {formate }}$ causes solubility in polar aprotic solvents such as DMF, DMAc, or DMSO. With increasing $\mathrm{DS}_{\text {laurate, }}$, the samples become soluble in non-polar solvents such as tetrahydrofuran, acetone, ethyl acetate, and chloroform.

The starch formate laurates possess thermoplastic properties without addition of any softener. The melting ranges are slightly dependent on the total DS only; however, they strongly depend on the amount of laurate moieties $\left(\mathrm{DS}_{\text {laurate }}\right.$. The higher the $\mathrm{DS}_{\text {laurate, }}$, the lower the melting range. Sample 3d with a $\mathrm{DS}_{\text {laurate }}$ of 0.11 only does not show melting at all, whereas sample 3a with a DS laurate of 2.53 melts at around $125^{\circ} \mathrm{C}$. 
Table 2. Degree of substitution (DS) and melting area of products obtained by the conversion of starch formates (2a-d) with lauroyl chloride in $\mathrm{N}, \mathrm{N}$-dimethylacetamide at $80{ }^{\circ} \mathrm{C}$ for $3 \mathrm{~h}$.

\begin{tabular}{|c|c|c|c|c|c|c|c|}
\hline \multicolumn{2}{|c|}{ Starch Formate } & \multirow{2}{*}{$\begin{array}{l}\text { Molar Ratio of } \\
\text { ModifiedAGU: } \\
\text { Lauroyl Chloride }\end{array}$} & \multicolumn{5}{|c|}{ Starch Formate Laurate } \\
\hline No. & DS & & No. & $D_{\text {formate }}$ & $\mathrm{DS}_{\text {laurate }}$ & $\mathrm{DS}_{\text {tot }}$ & $\begin{array}{c}\text { Melting } \\
{\left[{ }^{\circ} \mathrm{C}\right]}\end{array}$ \\
\hline $2 a$ & 0.97 & $1: 3$ & $3 a$ & 0.47 & 2.53 & 3.00 & $125-150$ \\
\hline $2 b$ & 1.86 & $1: 2$ & $3 b$ & 1.31 & 1.15 & 2.46 & $150-175$ \\
\hline $2 c$ & 2.15 & $1: 2$ & $3 c$ & 1.58 & 0.75 & 2.33 & $160-185$ \\
\hline $2 d$ & 2.44 & $1: 1$ & $3 d$ & 2.51 & 0.11 & 2.62 & no melting \\
\hline
\end{tabular}

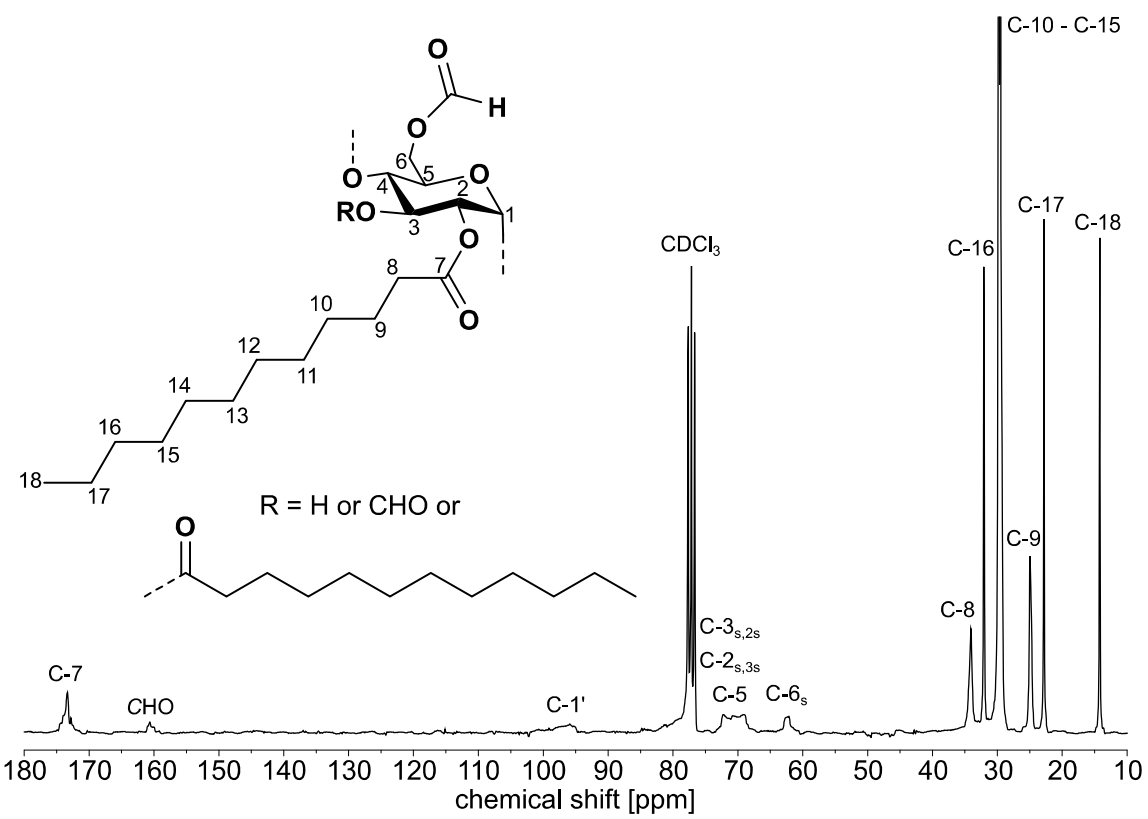

Figure 5. ${ }^{13} \mathrm{C}$ NMR spectrum $\left(62.90 \mathrm{MHz}, 297 \mathrm{~K}, \mathrm{CDCl}_{3}\right)$ of starch formate laurate $3 a$ acquired in $\mathrm{CDCl}_{3}\left(\mathrm{DS}_{\text {formate }}=0.47, \mathrm{DS}_{\text {laurate }}=2.53\right)$.

\section{Discussion}

The NMR measurements revealed that the initially reactive position 3 hardly takes part in the reaction until the other two hydroxyl groups are completely esterified. Thus, positions 2 and 6 are esterified with a certain regioselectivity. The signals of the carbonyl carbon atoms are in the range of around $161 \mathrm{ppm}$. Compared to other carboxylic acid esters of starch, they are thus shifted into the high field by approximately $10 \mathrm{ppm}$.

No hydrolysis of the formic acid esters could be detected. Therefore, it can be concluded that the starch formates are more resistant to hydrolysis than previously assumed. The test could not be repeated with pure water because none of the derivatives were soluble in water due to their hydrophobic nature.

Starch formates do not possess thermoplastic properties, i.e., neither melting nor softening could be observed. However, no decomposition occurred by heating the samples up to $230{ }^{\circ} \mathrm{C}$, which proves the thermal stability of this starch ester. On the contrary, the melting properties are governed by the fatty acid moiety, and the introduction of those long-chain moieties reduces the softening temperature remarkably. As already suspected from the investigation of the pure starch formates, the effect of the formic acid moieties is extremely weak and the formate moiety is not sufficient to generate thermoplastic starch esters. 


\section{Materials and Methods}

Dimethyl sulfoxide (DMSO, 99.7\%, extra dry over molecular sieve), $\mathrm{N}, \mathrm{N}$-dimethyl formamide (DMF, $99.8 \%$, extra dry), and $\mathrm{N}, \mathrm{N}$-dimethylacetamide (DMAc, $99.5 \%$, extra dry over molecular sieve) were purchased from Acros Organics. 1,1'-Carbonyldiimidazole $(>97 \%)$ was available from Fluka. Formic acid $(>98 \%)$ was obtained from Carl Roth, Germany. Deuterated solvents were purchased from Deutero GmbH. Maize starch (FLOJEL 60 , purchased from Ingredion) was dried for $8 \mathrm{~h}$ at $110^{\circ} \mathrm{C}$ in vacuum before use.

Fourier transform infrared (FTIR) spectra were recorded as $\mathrm{KBr}$ pellets on a Shimadzu IRAffinity-1 (Shimadzu, Duisburg, F.R. Germany); a total of 64 measurements were accumulated with a resolution of $1 \mathrm{~cm}^{-1}$.

Nuclear magnetic resonance (NMR) spectra were recorded on a Bruker $250 \mathrm{MHz}$ Avance I spectrometer (Billerica, MA, USA). Samples were prepared by dissolving $55 \mathrm{mg}$ of the substance in $550 \mu \mathrm{L}$ deuterated solvent. For ${ }^{13} \mathrm{C}$ NMR spectra, more than 10,000 scans were accumulated. The chemical shifts are given in parts per million (ppm) and calibrated with tetramethylsilane (TMS).

The degree of substitution (DS) of formate groups was determined by applying conductometric titration after alkaline hydrolysis of the sample. For this purpose, $650 \mathrm{mg}$ of the sample was added into in $25 \mathrm{~mL}$ sodium hydroxide solution $\left(0.5 \mathrm{~mol} \mathrm{~L}^{-1}\right)$ for $16 \mathrm{~h}$ at $60{ }^{\circ} \mathrm{C}$ under stirring. Aliquots of $10 \mathrm{~mL}$ each were taken and titrated with hydrochloric acid. The three areas of the curve were approximated with linear regressions and the intersections of the regressions gave $\Delta \mathrm{V}$. The DS value was calculated as the mean value of two separate measurements.

$$
\mathrm{wt} \%_{\text {formate }}=\frac{\Delta \mathrm{V} \cdot \mathrm{c}_{\text {measuring solution }} \cdot \mathrm{M}_{\text {formate }}}{\mathrm{m}_{\text {sample }}} \cdot 100 \%
$$

where wt \% formate-mass fraction of the formate substituents of the whole sample; $\Delta \mathrm{V}$-for titration of the formate substituent necessary volume of measuring solution in $\mathrm{L}$; $\mathrm{C}_{\text {measuring solution }}$-substance concentration of the measurement solution in $\mathrm{mol} \mathrm{L}^{-1}$; $\mathrm{M}_{\text {formate }}-29.02 \mathrm{~g} \mathrm{~mol}^{-1} ; \mathrm{m}_{\text {sample }}$-mass of the sample in $\mathrm{g}$.

$$
\mathrm{DS}_{\text {formate }}=\frac{\mathrm{m}_{\mathrm{AGU}}}{\frac{100 \cdot \mathrm{M}_{\text {formate }}}{\mathrm{wt} \%_{\text {formate }}}-\mathrm{M}_{\text {formate }}+1.008 \mathrm{~g} \cdot \mathrm{mol}^{-1}}
$$

where $\mathrm{M}_{\mathrm{AGU}}$-molar mass of the anhydroglucose unit $\left(162.15 \mathrm{~g} \mathrm{~mol}^{-1}\right)$.

Thermal behaviour was examined applying a hot stage microscope.

For the test of hydrolytic stability, $500 \mathrm{mg}$ of $\mathbf{2 d}(\mathrm{DS}=2.44,2.17 \mathrm{mmol})$ were dissolved

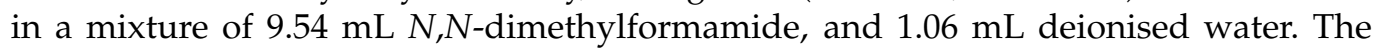
mixture was magnetically stirred for $3 \mathrm{~h}$ at ambient temperature. The $\mathrm{pH}$ value was monitored continuously.

\subsection{Synthesis of Starch Formate $\mathbf{2 a - 2 f}$}

In a typical example, 1,1'-carbonyldiimidazole $(25.00 \mathrm{~g}, 154.19 \mathrm{mmol})$ was allowed to react with formic acid $(5.82 \mathrm{~mL}, 154.19 \mathrm{mmol})$ in $91 \mathrm{~mL}$ DMSO for one hour at ambient temperature and, additionally, $30 \mathrm{~min}$ at $60^{\circ} \mathrm{C}$. The resulting clear solution was added to a solution of starch $(5.00 \mathrm{~g}, 30.84 \mathrm{mmol})$ in $40 \mathrm{~mL}$ DMSO. The mixture was magnetically stirred for $3 \mathrm{~h}$ at $60^{\circ} \mathrm{C}$. After cooling to room temperature, the mixture was poured into $1000 \mathrm{~mL}$ chloroform. The precipitate was filtered off, washed six times with $200 \mathrm{~mL}$ chloroform each, and was dried in vacuum at $40{ }^{\circ} \mathrm{C}$.

Product: 2d

Yield: $6.58 \mathrm{~g}$ (28.55 mmol modified AGU, 93\% of theoretical yield).

DS: 2.44 (49\% efficiency).

Elemental analysis found [\%]: $\mathrm{C}=43.63, \mathrm{H}=4.28, \mathrm{~N}=0.59$.

${ }^{1} \mathrm{H}$ NMR $\left(250.13 \mathrm{MHz}, 323 \mathrm{~K}, \mathrm{DMSO}-d_{6}\right.$ ) [ppm]: $\delta=8.23$ (-CHO), 5.5-3.5 (AGU). 
${ }^{13} \mathrm{C}$ NMR $\left(62.90 \mathrm{MHz}, 323 \mathrm{~K}, \mathrm{DMSO}-d_{6}\right)[\mathrm{ppm}]: \delta=162-160$ (C 7), 97.04 (C $\left.1^{\prime}\right)$, 75.53 (C 4), 72.20 (C 3s), 70.14 (C 2s), 69.02 (C 5), 61.96 (C 6 s ).

\subsection{Synthesis of Starch Formate Laurate 3a-3d}

To a solution of starch formate $2 \mathbf{a}(1.00 \mathrm{~g}$, DS: $0.97,5.28 \mathrm{mmol})$ in $25 \mathrm{~mL}$ DMAc, lauroyl chloride $(3.77 \mathrm{~mL}, 15.84 \mathrm{mmol})$ was added and the mixture was allowed to react for $3 \mathrm{~h}$ at $80^{\circ} \mathrm{C}$ under stirring. After cooling to room temperature, the mixture was poured into $250 \mathrm{~mL}$ methanol. The precipitated formed was filtered off, washed four times with $100 \mathrm{~mL}$ methanol each, and was dried in vacuum at $40^{\circ} \mathrm{C}$.

Product: $3 \mathbf{a}$

Yield: $2.08 \mathrm{~g}$ (3.27 mmol modified AGU, $62 \%$ of theoretical yield).

$\mathrm{DS}_{\text {formate }}$ : $0.48, \mathrm{DS}_{\text {laurate }}: 2.51$.

${ }^{1} \mathrm{H}$ NMR (250.13 MHz, $297 \mathrm{~K}, \mathrm{CDCl}_{3}$ ) [ppm]: $\delta=8.10$ (CHO), 5.75-3.50 (AGU), 2.35 (H 8), 1.51 (H 9), 1.25 (H 10-H 17), 0.87 (H 18).

${ }^{13} \mathrm{C}$ NMR $\left(62.90 \mathrm{MHz}, 297 \mathrm{~K}, \mathrm{CDCl}_{3}\right)$ [ppm]: $\delta=173.37$ (C $\left.7_{\text {laurate }}\right), 160.65(\mathrm{CHO})$, 95.93 (C 1'), 72.20-68.98 (C 3s, $2_{\mathrm{s}}, \mathrm{C} 2_{\mathrm{s}}, 3_{\mathrm{s}}, \mathrm{C} \mathrm{5}$ ), 62.31 (C 6s), 34.09 (C 8), 32.08 (C 16), 29.54 (C 10-C 15), 24.97 (C 9), 22.81 (C 17), 14.23 (C 18).

\section{Conclusions}

An efficient process for the preparation of pure starch formates by conversion of starch with $N$-formyl imidazole obtained by the reaction of formic acid with 1,1'-carbonyldiimidazole was developed yielding highly substituted products with DS of up to 2.55. The starch formates are soluble in polar aprotic solvents, unexpectedly stable against hdrolysis, and do not melt. However, the conversion of the starch formates by subsequent reaction with lauric acid chloride, e.g., yields mixed starch esters that are thermoplastic and melt at low temperature of $125^{\circ} \mathrm{C}$ to $185^{\circ} \mathrm{C}$, depending on the DS values. The thermoplastic properties of these novel materials are under investigation.

Formate groups could act as protecting groups for the hydroxyl groups. Moreover, starch formate may act as a polymer-bound CO surrogate or CO-releasing molecule for application in organic synthesis (e. g., hydroesterification [18]) or in medical applications that are under investigation.

Author Contributions: Conceptualisation, T.H.; methodology, S.B., H.Q.; validation, T.H., H.Q.; formal analysis, S.B.; investigation, S.B., H.Q.; resources, T.H.; data curation, H.Q.; writing-original draft preparation, S.B.; writing-review and editing, H.Q.; visualisation, S.B.; supervision, T.H.; project administration, T.H.; funding acquisition, T.H. All authors have read and agreed to the published version of the manuscript.

Funding: This research received no external funding.

Institutional Review Board Statement: Not applicable.

Informed Consent Statement: Not applicable.

Data Availability Statement: The data presented in this study are available on request from the corresponding author.

Acknowledgments: We would like to acknowledge the NMR platform at the Friedrich-Schiller University Jena for support in the NMR spectroscopy. The authors appreciate the proofreading by A. Koschella.

Conflicts of Interest: The authors declare no conflict of interest.

Sample Availability: Not available. 


\section{References}

1. Carmona-Garcia, R.; Sanchez-Rivera, M.M.; Méndez-Montealvo, G.; Garza-Montoya, B.; Bello-Pérez, L.A. Effect of the crosslinked reagent type on some morphological, physicochemical and functional characteristics of banana starch (Musa paradisiaca). Carbohydr. Polym. 2009, 76, 117-122. [CrossRef]

2. Vanmarcke, L.; Leroy, L.; Stoclet, G.; Duchatel-Crépy, L.; Lefebvre, J.-M.; Joly, N.; Gaucher, V. Influence of fatty chain length and starch composition on structure and properties of fully substituted fatty acid starch esters. Carbohydr. Polym. 2017, 164, 249-257. [CrossRef] [PubMed]

3. Barrios, S.E.; Giammanco, G.; Contreras, J.M.; Laredo, E.; López-Carrasquero, F. Characterization of esterified cassava starch with long alkyl side chains and different substitution degrees. Int. J. Biol. Macromol. 2013, 59, 384-390. [CrossRef] [PubMed]

4. Liebert, T.; Klemm, D.; Heinze, T. Synthesis and carboxymethylation of organo-soluble trifluoroacetates and formates of cellulose. J. Macromol. Sci. Part A 1996, 33, 613-626. [CrossRef]

5. Heinze, T.; Heinze, U. The first approach to non-aqueous solutions of carboxymethylcellulose. Macromol. Rapid Commun. 1997, 18, 1033-1040. [CrossRef]

6. Gottlieb, D.; Caldwell, C.; Hixon, R. Action of formic acid on starch. J. Am. Chem. Soc. 1940, 62, 3342-3344. [CrossRef]

7. Tarkow, H.; Stamm, A.J. The reaction of formic acid with carbohydrates. II. Polysaccharides: A new method for determining accessibility. J. Phys. Chem. 1952, 56, 266-271. [CrossRef]

8. Wolff, I.; Olds, D.; Hilbert, G. Starch formate. J. Am. Chem. Soc. 1957, 79, 3860-3862. [CrossRef]

9. Divers, T.; Pillin, I.; Feller, J.-F.; Levesque, G.; Grohens, Y. Starch modification, destructuration and hydrolysis during Oformylation. Starch/Stärke 2004, 56, 389-398. [CrossRef]

10. Pillin, I.; Divers, T.; Feller, J.-F.; Grohens, Y. Elaboration and characterization of starch/poly(caprolactone) blends. Macromol. Symp. 2005, 222, 233-238. [CrossRef]

11. Divers, T.; Balnois, E.; Feller, J.-F.; Spevacek, J.; Grohens, Y. The influence of O-formylation on the scale of starch macromolecules association in DMSO and water. Carbohydr. Polym. 2007, 68, 136-145. [CrossRef]

12. Bossard, F.; Pillin, I.; Aubry, T.; Grohens, Y. Rheological characterization of starch derivatives/polycaprolactone blends processed by reactive extrusion. Polym. Eng. Sci. 2008, 48, 1862-1870. [CrossRef]

13. Spěváček, J.; Brus, J. Solid-state NMR studies of polysaccharide systems. Macromol. Symp. 2008, 265, 69-76. [CrossRef]

14. Lancuški, A.; Vasilyev, G.; Putaux, J.-L.; Zussman, E. Rheological properties and electrospinnability of high-amylose starch in formic acid. Biomacromolecules 2015, 16, 2529-2536. [CrossRef] [PubMed]

15. Lancuški, A.; Abu Ammar, A.; Avrahami, R.; Vilensky, R.; Vasilyev, G.; Zussman, E. Design of starch-formate compound fibers as encapsulation platform for biotherapeutics. Carbohydr. Polym. 2017, 158, 68-76. [CrossRef] [PubMed]

16. Staab, H.A.; Polenski, B. Heterocyclische Amide der Ameisensäure. Justus Liebigs Ann. Chem. 1962, 655, 95-102. [CrossRef]

17. Powers, R.M.; Tetenbaum, M.T.; Tai, H. Determination of aliphatic formates by near infrared spectrophotometry. Anal. Chem. 1962, 34, 1132-1134. [CrossRef]

18. Konishi, H.; Manabe, K. Formic acid derivatives as practical carbon monoxide surrogates for metal-catalyzed carbonylation reactions. Synlett 2014, 25, 1971-1986. [CrossRef] 